\title{
Hypertension and Diabetes
}

\section{What are the pros to treating early surrogates?}

Roland E. Schmieder, MD

I n recent years, the British Medical Journal published several papers apropos the "parachute approach evidencebased medicine" (1). In the original profound article, Smith and Pell argued that the parachute use to prevent death and major trauma due to capital challenge is clearly obvious, and there is no need for randomized controlled trials (2). Although this argument may hold true in medicine for only few situations, waiting for the results of randomized end point trials of therapeutic interventions can cost hundred of lives under certain circumstances. If the science is good, we should act before trials are performed using intermediate end points or "surrogates" as therapeutic targets. Indeed, surrogate parameters have emerged as most helpful tools for an evidence-based approach for therapeutic decisions in cardiovascular medicine. The ensuing article outlines the pro arguments that surrogates are most acceptable targets for treating patients with hypertension and diabetes.

\section{ELICIBILITY OF}

SURROGATES - According to Merriam Webster's dictionary, the meaning of surrogate is "one appointed to act in place of another" and "one that serves as a substitute." In the 2007 European Society of Hypertension Guidelines (3), the word "surrogate" is replaced by the wording "intermediate end point," thereby pointing to the fact that, in hypertensive disease, a surrogate in general reflects early structural or functional changes of the vascular, renal, or cardiac tissue due to the presence of cardiovascular risk factors. More specifically, certain requirements for clinical use of organ damage measures should be fulfilled before a clinical parameter is considered an interme- diate end point or surrogate for fatal or nonfatal cardiovascular complications. These eligibility criteria are as follows: the surrogate must be a sensitive and common marker of early damage in cardiovascular disease, should ideally be measured noninvasively, should have a high reproducibility (low between/within-observer variability), the assessment must be (worldwide) standardized, and evidence of prognostic importance of the selected surrogate parameter should be documented in several populations. Moreover, and most importantly, reduction of surrogate parameters for organ damage should be associated with improved cardiovascular and renal prognosis as evidenced in more than one prospective randomized clinical trial.

According to current guidelines and practice by the authorities for drug approval (Europe, Middle East, and Africa [EMEA], Food and Drug Administration), the biomarkers (blood pressure, blood glucose, and serum lipid concentrations) are accepted as surrogates in the field of hypertension and diabetes. The justification for acceptance of these parameters (all are more biomarkers than surrogate parameters of organ damage measures) is based on epidemiological evidence, documented pathogenetic links between these biomarkers and cardiovascular damage, and most salient, the evidence that reduction of these biomarkers is associated with improved cardiovascular prognosis and increased life expectancy. The weakness of this concept, at least from a clinical perspective, is that the accuracy of indicating incident of cardiovascular disease is poor. Overall, it has been clearly shown that $2 \mathrm{mmHg}$ reduction in blood pressure is related to a $7 \%$ reduction of myocardial infarction and a 10\%

$\bullet \bullet \bullet \bullet \bullet \bullet \bullet \bullet \bullet \bullet \bullet \bullet \bullet \bullet \bullet \bullet \bullet \bullet \bullet \bullet \bullet \bullet \bullet \bullet \bullet \bullet \bullet \bullet \bullet \bullet \bullet \bullet \bullet \bullet \bullet \bullet \bullet \bullet \bullet \bullet \bullet \bullet \bullet \bullet \bullet \bullet \bullet \bullet \bullet$

From the University Hospital Erlangen, Erlangen, Germany.

Corresponding author: Roland E. Schmieder, roland.schmieder@uk-erlangen.de.

The publication of this supplement was made possible in part by unrestricted educational grants from Eli Lilly, Ethicon Endo-Surgery, Generex Biotechnology, Hoffmann-La Roche, Johnson \& Johnson, LifeScan, Medtronic, MSD, Novo Nordisk, Pfizer, sanofi-aventis, and WorldWIDE.

DOI: $10.2337 / \mathrm{dc} 09-\mathrm{S} 356$

(C) 2009 by the American Diabetes Association. Readers may use this article as long as the work is properly cited, the use is educational and not for profit, and the work is not altered. See http://creativecommons. org/licenses/by-nc-nd/3.0/ for details. reduction of stroke (4). Although this finding is helpful from a general perspective, the precision/accuracy as to which of the hypertensive patients profit most from blood pressure-lowering intervention is inadequate and does not facilitate a tailored therapeutic approach.

Therefore, the question arises whether there are additional surrogates that can more precisely predict the cardiac, renal, or vascular prognosis of diabetic and hypertensive patients

\section{SURROGATES OF CARDIOVASCULAR-RENAL}

DAMAGE - More than 15 years ago, Dzau and Braunwald (5) introduced the concept of the cardiovascular continuum in medicine. Starting with the wellknown cardiovascular risk factors, such as diabetes, hypertension, and hyperlipidemia, early functional and structural changes in the renal and systemic vasculature occur as evidenced by vascular and endothelial dysfunction, atherosclerosis, and vascular and cardiac remodeling. If treatment remains inadequate for a longer period, myocardial infarction and stroke occur, ultimately leading to ventricular dilatation, congestive heart failure, and end-stage heart disease and eventually to cardiac and cerebrovascular death. Recently, we learned that parallel to the cardiovascular continuum, a similar renal continuum exists, starting with the same cardiovascular risk factors and leading to similar pathogenetic processes. Whereas microalbuminuria and macroalbuminuria/proteinuria reflect the intermediate stage of the renal continuum, decreased renal function and end-stage renal disease are at the far end of the renal continuum. A pivotal goal of treating cardiovascularrenal disease is to prevent the progression of the disease along the cardiovascular and renal scale. Identification of surrogate parameters within this range would help to specify the stage of cardiovascularrenal damage in individual patients and, therefore, provide the tool for individualized treatment strategies. In other words, the greater the cardiovascular and renal damage, the more aggressive and persistent the treatment strategy should be.

In the 2007 European Society of Hy- 


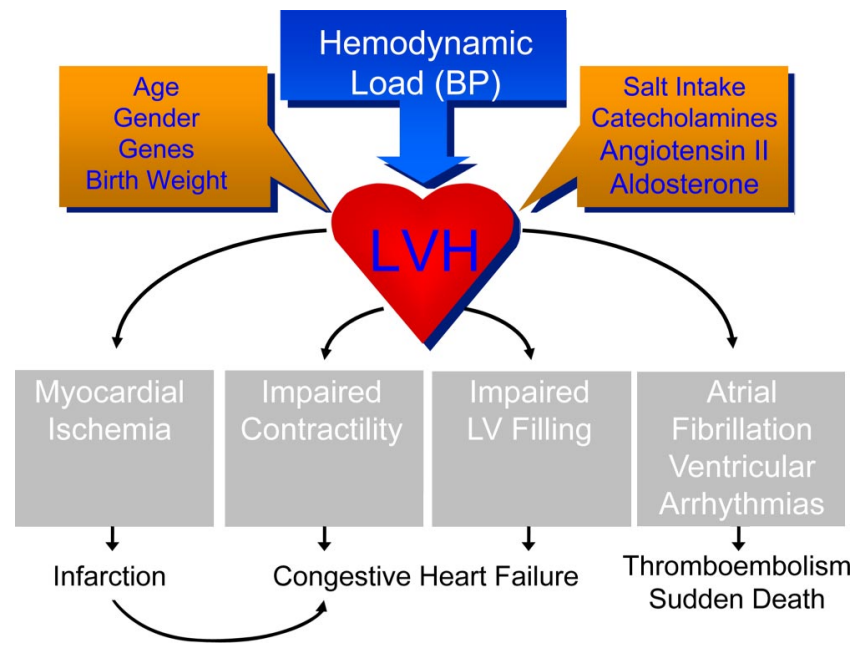

Figure 1-Hypertensive heart disease: pathogenetic determinants of LVH (top), its pathogenetic consequences (middle), and cardiovascular fatal and nonfatal events due to LVH (bottom).

pertension Guidelines, the requirements have been carefully defined (3). Several measures of subclinical cardiovascularrenal damage have been subsequently identified, and screening has been recommended for each hypertensive and diabetic patient. To identify early structural changes of the heart, left ventricular mass, relative wall thickness as a parameter for the concentric type of left ventricular hypertrophy (LVH), and left atrial remodeling were identified as surrogates fulfilling all requirements of intermediate end points (Fig. 1). For example, LVH is a specific and sensitive marker of early hypertensive heart disease and can easily be detected by electrocardiography and echocardiography (6). The assessment of LVH is standardized and according to several prospective trials, it has been documented as a major cardiovascular risk factor in the hypertensive, diabetic, and general population of various ages, sex, and ethnic origins. Furthermore, with progressive increase of left ventricular mass, the risk of cardiovascular events increases in parallel (7). Accordingly, intima-media thickness of the carotid arteries serves as an excellent surrogate of cardiovascular risk associated with carotid artery disease (8). In the systemic circulation, carotid-femoral pulse wave velocity was found to have predictive value for cardiovascular events in $>12$ studies comprising 13,000 subjects with various cardiovascular disorders at baseline (9).

The surrogate marker "increased albumin excretion" does not only indicate the development of chronic renal failure and end-stage renal disease, but serves also as an indicator for cardiovascular tion for Endpoint Reduction in Hypertension (LIFE) trial, increased albumin excretion, even in the normal range (the so-called low-grade albuminuria), is associated with increased cardiovascular event rate (11). In the general populationbased PREVEND study, there was a progressively enhanced risk of cardiovascular mortality with increased albumin concentration in the spot urine (12). Thus, increased urinary albumin excretion (lowgrade albuminuria, microalbuminuria, and macroalbuminuria) fulfils all the requirements of an ideal surrogate parameter for renal and cardiovascular disease (3). In particular, the simplicity of measuring urinary albumin excretion from the spot urine, as well as its high sensitivity and prognostic importance, has been well evidenced in the last 5-10 years.

\section{IMPROVED PROCNOSIS RELATED TO REVERSAL OF SURROGATE END POINTS - It} is a proven fact that the reduction of blood pressure, blood glucose, and serum LDL cholesterol levels are associated with improved cardiovascular, cerebrovascular, and renal prognosis. Such evidence has been documented in randomized controlled clinical prospective trials and has lead to the inclusion of these biomarkers in therapeutic recommendation of various international guidelines (3). Likewise, prospective trials using echocardiography to diagnose LVH have consistently found that regression of LVH results in a reduced cardiovascular event rate (13). In a meta-analysis, the odds ratio was 0.41 in prognosis (10). In the Losartan Interven- favor of LVH regression as opposed to LVH persistence. In the LIFE trial, regression of electrocardiographic evidence of LVH led to a highly significant reduction of cardiovascular mortality, myocardial infarction, stroke, and the composite end point. This finding was significant, since even after adjustment for treatment effect, baseline Framingham risk score, and baseline and in-treatment systolic and diastolic blood pressure, the hazard ratio of cardiovascular complications remained significantly reduced in favor of LVH regression (14).

In addition to the prognostic data, our pathogenetic understanding of hypertensive disease supports the concept that LVH is a valid surrogate for cardiac organ damage at a stage when the structural and functional changes can be reversed (intermediate end point). Several clinical studies have found that reduction of LVH leads to improved myocardial ischemia, improved systolic contractility, and improved left ventricular filling, reduced incidence of atrial fibrillation, and ventricular arrhythmia (6). All these cardiac impairments due to LVH predispose to myocardial infarction, congestive heart failure, thrombo-embolism, and cardiac sudden death (6). Conversely, it can be expected that reversal of these pathogenetic mechanisms result in improved cardiovascular prognosis. Thus, it is conceivable that also in the HOPE study, i.e., in patients at high risk of cardiovascular events, reduction of primary outcome (cardiovascular death, myocardial infarction, and stroke) was determined by the changes in LVH (15).

To date, only a few, but nevertheless, large prospective trials have substantiated the notion that reduction of albuminuria is linked to improved renal and cardiovascular prognosis. In the LIFE trial, comprising nearly 10,000 hypertensive patients with LVH, reduction of urinary albumin excretion within the first year (most occur even in the normoalbuminuric range) has been found to have a lower incidence of the composite end point of cardiovascular death, stroke, and myocardial infarction (16).

Similarly, in a study analyzing microalbuminuria and tubular proteinuria as risk predictors of cardiovascular morbidity and mortality in essential hypertension (MARPLE study), it was found that conversion of pathological albuminuria to normal-range albuminuria was associated with a reduced cardio- and cerebrovascular morbidity and total mortality (17). In 


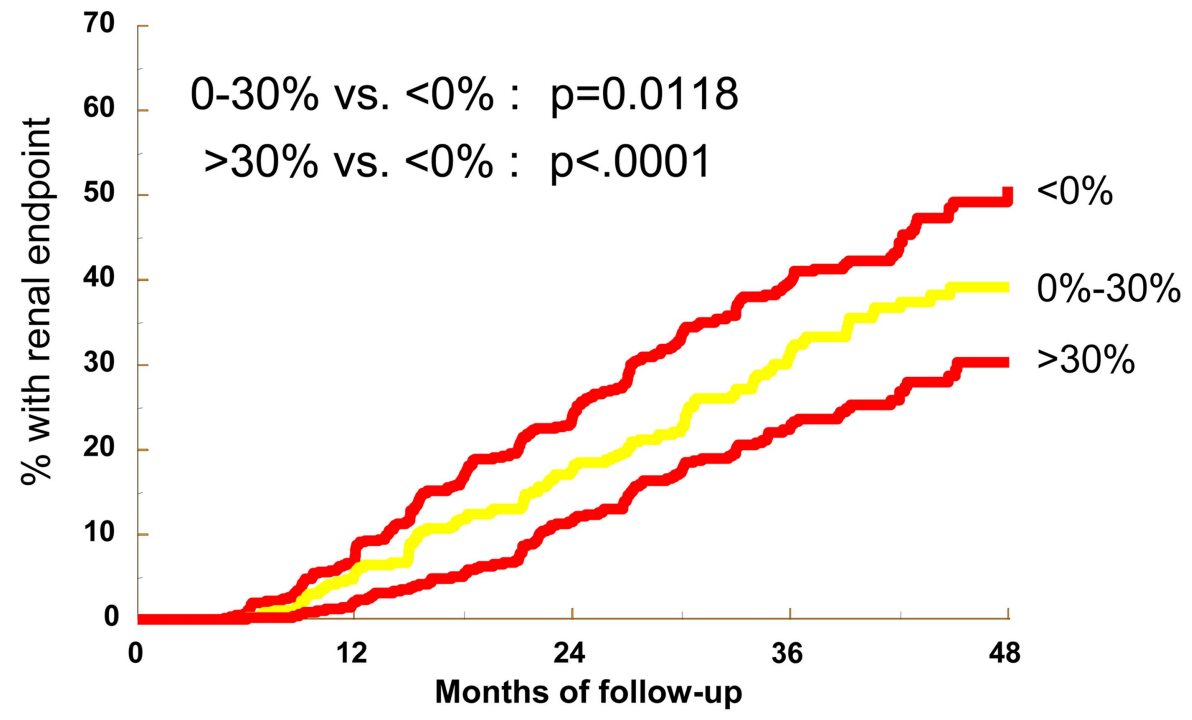

Figure 2-Reduction of albuminuria predicts renal end point. Adapted from de Zeeuw et al. (18).

the Reduction of Endpoints in NIDDM with the Angiotensin II Antagonist Losar$\tan$ (RENAAL) trial, the treatment of hypertensive patients with type 2 diabetes and overt proteinuria by effective blood pressure control with an angiotensin receptor blocker has been analyzed throughout follow-up of 2.6 years. In this trial, reduction of proteinuria of $>30 \%$ was highly significant and associated with reduced incidence of renal end points (mostly renal replacement therapy) (18) and, in parallel, to improved cardiovascular prognosis with respect to the cardiovascular combined end point, as well as to congestive heart failure (19) (Fig. 2).

Thus, with respect to LVH and albuminuria, we have solid evidence that reduction of these surrogates is followed by a lower incidence of cardiovascular and renal complications.

\section{THE VALUE OF SURROGATES IN CLINICAL}

PRACTICE - Identification of surrogates in clinical practice facilitates diagnosis of organ damage at a stage when fatal consequences can be avoided by adequate treatment. Moreover, the stage within the cardiovascular and renal continuum can be identified for each individual patient and, consequently, individualized treatment strategies may be applied. The treatment of LVH should be preferably carried out with calcium antagonists, ACE inhibitors, and/or angiotensin receptor blockers, since they have been found to be superior to diuretics and $\beta$-receptor blockers in reducing LVH (20). It is of interest that even after $>5$ years of treat- ment, the significant difference in regression of LVH persisted between the treatment strategies with $\beta$-receptor blockers, as opposed to angiotensin receptor blockers (21). Accordingly, hypertensive patients with diabetes and elevated urinary albumin excretion should preferably be treated with ACE inhibitors and angiotensin receptor blockers (3). These recommendations are based on several clinical trials and meta-analyses. The studies uniformly demonstrated that the mentioned preferential drug classes have organprotective effects beyond those of their effect on blood pressure alone.

The assessment of surrogates in longterm treatment is a clinically helpful tool to ensure the patient's adherence to the regimen. Reduction of albuminuria or LVH after several months should be conveyed to the patient as an indicator of improved structure and function in the respective organ. Long-term adherence is essential for the effectiveness of any treatment strategy, and the measurement of surrogates represents a tool for individualized treatment approaches and helps to improve the patient's adherence. In contrast to the assessment of vascular risk scores that represent a more general approach of risk assessment, identification of early organ damage along the cardiovascular and renal continuum enables the physician to use an individualized approach that is clearly preferential. This facilitates a tailored medication to treat to the detected organ damage.

CONCLUSIONS - Only few clinical parameters fulfill the requirements for ac- ceptance as a surrogate of organ damage in cardiovascular medicine. Undoubtedly, left ventricular hypertrophy, albuminuria, and to a lesser extent, parameters of vascular stiffening (e.g., pulse wave velocity) represent clinically helpful tools to adequately diagnose hypertensive diabetic patients and to modify their treatment on an individual basis. Treatment of surrogates further represents helpful tools to monitor the success of therapy and adherence to the administered medication.

Acknowledgments - No potential conflicts of interest relevant to this article were reported.

\section{References}

1. Potts M, Prata N, Walsh J, Grossman A. Parachute approach to evidence based medicine. BMJ 2006;333:701-703

2. Smith GC, Pell JP. Parachute use to prevent death and major trauma related to gravitational challenge: systematic review of randomised controlled trials. BMJ 2003;327:1459-1461

3. Mancia G, De Backer G, Dominiczak A, Cifkova R, Fagard R, Germano G, Grassi G, Heagerty AM, Kjeldsen SE, Laurent S, Narkiewicz K, Ruilope L, Rynkiewicz A, Schmieder RE, Boudier HA, Zanchetti A, Vahanian A, Camm J, De Caterina R, Dean V, Dickstein K, Filippatos G, Funck-Brentano C, Hellemans I, Kristensen SD, McGregor K, Sechtem U, Silber S, Tendera M, Widimsky P, Zamorano JL, Erdine S, Kiowski W, Agabiti-Rosei E, Ambrosioni E, Lindholm LH, Viigimaa M, Adamopoulos S, Bertomeu V, Clement D, Farsang C, Gaita D, Lip G, Mallion JM, Manolis AJ, Nilsson PM, O’Brien E, Ponikowski P, Redon J, Ruschitzka F, Tamargo J, van Zwieten P, Waeber B, Williams B. 2007 Guidelines for the Management of Arterial Hypertension: The Task Force for the Management of Arterial Hypertension of the European Society of Hypertension (ESH) and of the European Society of Cardiology (ESC). J Hypertens 2007;25: 1105-1187

4. Lewington S, Clarke R, Qizilbash N, Peto R, Collins R. Age-specific relevance of usual blood pressure to vascular mortality: a meta-analysis of individual data for one million adults in 61 prospective studies. Lancet 2002;360:1903-1913

5. Dzau V, Braunwald E. Resolved and unresolved issues in the prevention and treatment of coronary artery disease: a workshop consensus statement. Am Heart J 1991;121:1244-1263

6. Ruilope LM, Schmieder RE. Left ventricular hypertrophy and clinical outcomes in hypertensive patients. Am J Hypertens 2008;21:500-508 
7. Schillaci G, Verdecchia P, Porcellati C, Cuccurullo O, Cosco C, Perticone F. Continuous relation between left ventricular mass and cardiovascular risk in essential hypertension. Hypertension 2000;35:580-586

8. O'Leary DH, Polak JF, Kronmal RA, Manolio TA, Burke GL, Wolfson SK Jr: Carotid-artery intima and media thickness as a risk factor for myocardial infarction and stroke in older adults: Cardiovascular Health Study Collaborative Research Group. N Engl J Med 1999; 340:14-22

9. Laurent S, Boutouyrie P. Arterial stiffness: a new surrogate end point for cardiovascular disease? J Nephrol 2007;20 (Suppl. 12):S45-S50

10. Schmieder RE, Schrader J, Zidek W, Tebbe U, Paar WD, Bramlage P, Pittrow $\mathrm{D}$, Bohm M. Low-grade albuminuria and cardiovascular risk: what is the evidence? Clin Res Cardiol 2007;96:247-257

11. Wachtell K, Ibsen H, Olsen MH, BorchJohnsen K, Lindholm LH, Mogensen CE, Dahlof B, Devereux RB, Beevers G, de Faire U, Fyhrquist F, Julius S, Kjeldsen SE, Kristianson K, Lederballe-Pedersen O, Nieminen MS, Okin PM, Omvik P, Oparil S, Wedel H, Snapinn SM, Aurup P. Albuminuria and cardiovascular risk in hypertensive patients with left ventricular hypertrophy: the LIFE study. Ann Intern Med 2003;139:901-906

12. Hillege HL, Fidler V, Diercks GF, van Gilst WH, de Zeeuw D, van Veldhuisen DJ, Gans RO, Janssen WM, Grobbee DE, de Jong PE. Urinary albumin excretion predicts cardiovascular and noncardiovascular mortality in general population. Circulation 2002;106:1777-1782

13. Verdecchia P, Angeli F, Borgioni C, Gattobigio R, de Simone G, Devereux RB, Porcellati C. Changes in cardiovascular risk by reduction of left ventricular mass in hypertension: a meta-analysis. Am J Hypertens 2003;16:895-899

14. Okin PM, Devereux RB, Jern S, Kjeldsen SE, Julius S, Nieminen MS, Snapinn S, Harris KE, Aurup P, Edelman JM, Wedel $\mathrm{H}$, Lindholm LH, Dahlof B. Regression of electrocardiographic left ventricular hypertrophy during antihypertensive treatment and the prediction of major cardiovascular events. JAMA 2004;292: 2343-2349

15. Mathew J, Sleight P, Lonn E, Johnstone D, Pogue J, Yi Q, Bosch J, Sussex B, Probstfield J, Yusuf S. Reduction of cardiovascular risk by regression of electrocardiographic markers of left ventricular hypertrophy by the angiotensin-converting enzyme inhibitor ramipril. Circulation 2001;104:16151621

16. Ibsen H, Olsen MH, Wachtell K, BorchJohnsen K, Lindholm LH, Mogensen CE, Dahlof B, Devereux RB, de Faire U, Fyhrquist F, Julius S, Kjeldsen SE, LederballePedersen $\mathrm{O}$, Nieminen MS, Omvik P, Oparil S, Wan Y. Reduction in albuminuria translates to reduction in cardiovascular events in hypertensive patients: losartan intervention for endpoint reduction in hypertension study. Hypertension 2005;45:198-202

17. Schrader J, Luders S, Kulschewski A,
Hammersen F, Zuchner C, Venneklaas U, Schrandt G, Schnieders M, Rangoonwala B, Berger J, Dominiak P, Zidek W. Microalbuminuria and tubular proteinuria as risk predictors of cardiovascular morbidity and mortality in essential hypertension: final results of a prospective longterm study (MARPLE Study). J Hypertens 2006;24:541-548

18. de Zeeuw D, Remuzzi G, Parving HH, Keane WF, Zhang Z, Shahinfar S, Snapinn S, Cooper ME, Mitch WE, Brenner BM. Proteinuria, a target for renoprotection in patients with type 2 diabetic nephropathy: lessons from RENAAL. Kidney Int 2004:65:2309-2320

19. de Zeeuw D, Remuzzi G, Parving HH, Keane WF, Zhang Z, Shahinfar S, Snapinn S, Cooper ME, Mitch WE, Brenner BM. Albuminuria, a therapeutic target for cardiovascular protection in type 2 diabetic patients with nephropathy. Circulation 2004;110:921-927

20. Klingbeil AU, Schneider M, Martus P, Messerli FH, Schmieder RE. A meta-analysis of the effects of treatment on left ventricular mass in essential hypertension. Am J Med 2003;115:41-46

21. Okin PM, Devereux RB, Jern S, Kjeldsen SE, Julius S, Nieminen MS, Snapinn S, Harris KE, Aurup P, Edelman JM, Dahlof B. Regression of electrocardiographic left ventricular hypertrophy by losartan versus atenolol: the Losartan Intervention for Endpoint Reduction in Hypertension (LIFE) Study. Circulation 2003; 108:684-690 